回回回回回回回回回回回回回回回回回回回回回回回回

Problemy istorii, filologii, kul'tury 4 (2017), 14-30

Проблемы истории, филологии, культуры

(C) The Author(s) 2017

4 (2017), 14-30

(C)Автор(ы) 2017

\author{
О ЦАРСКОМ КУЛЬТЕ В ПАРФИИ \\ (на примере булл из раскопок Гебеклы-депе)
}

\author{
В.А. Гаибов \\ Институт археологии РАН, Москва, Россия \\ gaibov@mail.ru
}

Аннотация. В статье рассматривается группа оттисков печатей - булл, - обнаруженных при раскопках центрального здания пограничной крепости парфянского времени Гебеклы-депе на северо-западной окраине Мервского оазиса (античной Маргианы). Буллы были найдены между промазками полов обводных коридоров, служивших складскими помещениями, где вскрывались товары и грузы, прибывавшие в крепость из столичного центра сатрапии - Александрии/Антиохии Маргианской. Особое внимание привлекает представительная группа булл с сюжетами «идеологической» направленности, суть которой заключалась в прославлении (и обожествлении) царя и царской власти. Наиболее показательными с рассматриваемой точки зрения являются буллы с изображением царявсадника перед алтарем огня с орлом за спиной, держащим в клюве ленту-диадему; сидящего на троне царе с Никой, вручающей ему диадему; битвы царя-всадника с пехотинцем. Однако наиболее показательным примером прославления (и обожествления) царской власти является небольшая (4 экз.) группа булл с изображением сцены инвеституры богиней Тюхе царя перед алтарем (огня?). Наличие надписей за спинами персонажей подтверждает высокий статус чиновника - владельца данной печати.

Ключевые слова: Парфия, Маргиана, Гебеклы-депе, оттиски печатей, буллы, царский культ

На протяжении двух десятилетий - с 1981 по 2001 гг. - Среднеазиатская экспедиция ИА РАН под руководством Г.А. Кошеленко осуществляла раскопки городища Гебеклы-депе в Каракумском этрапе Марыйского велаята Туркменистана ${ }^{1}$. Памятник, впервые зафиксированный в ходе разведочных маршрутов ЮТАКЭ, был интерпретирован как небольшой город раннепарфянского времени ${ }^{2}$, однако масштабные работы, проведенные Среднеазиатской экспедицией, позволили уточнить характер и историю памятника. Первое поселение возникло здесь, очевидно, на позднем этапе раннего железного века, но основное время жизни памятника приходится на парфянский и раннесасанидский периоды.

\footnotetext{
Гаибов Васиф Абидович - кандидат исторических наук, старший научный сотрудник Отдела классической археологии ИА РАН.

1 Кошеленко, Никитин 1991, 108-121; Новиков, Новикова, Кошеленко 1994, 69-76; Гаибов, Кошеленко 2007, 360-374.

2 Пугаченкова 1958, 44-45.

C IA RAS, NMSTU, JHPhCS, 2017| DOI 10.18503/1992-0431-2017-4-58-14-30
} 


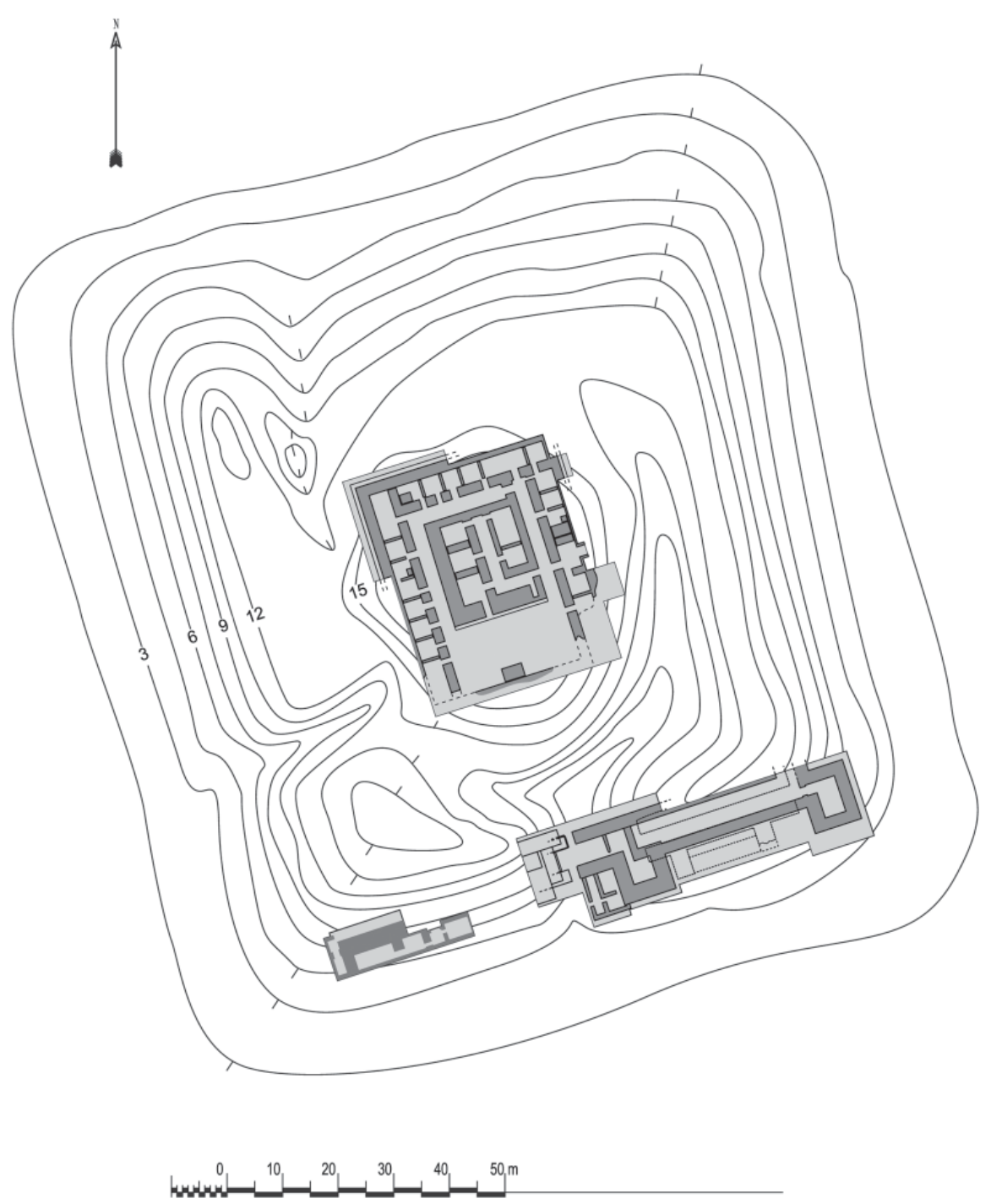

Рис. 1. Гебеклы-депе. Генеральный план

В это время он представлял собой небольшую (100 х 100 м) крепость, расположенную на границе оазиса и песков. Внутри периметра стен, на холме, было возведено прямоугольное в плане здание размерами 45 х 37,5 м (рис. 1), являвшееся, очевидно, резиденцией командира гарнизона данной крепости. При этом центральный комплекс, состоявший из пяти жилых комнат, был окружен системой двойных обводных коридоров, окружавших его с трех сторон. С четвертой, южной стороны, располагался единственный вход в здание с обширным двором (айваном) перед ним (рис.2). Обводные коридоры, разделенные позднее на от- 
дельные помещения-отсеки, служили для проживания обслуживающего персонала $^{3}$ и, главным образом, в качестве складских помещений для поступавших в крепость товаров и грузов. Именно в этих коридорах было обнаружено свыше 3000 экземпляров глиняных объектов с оттисками печатей - булл (цифра весьма приблизительная). Большинство из них дошли до нас во фрагментированном виде, поскольку буллы опечатывали различные контейнеры с грузами (кувшины, короба, тюки и т.п.) и при вскрытии их разламывали, зачастую непосредственно по изображению. Коллекция булл из Гебеклы-депе является на сегодняшний день крупнейшей среди аналогичных находок в центральноазиатском регионе, датируемых парфянским временем. Отдельным сюжетам и сюжетным группам, представленным на данных оттисках печатей, был посвящен ряд публикаций ${ }^{4}$.

Проведенный (далеко не полный) иконографический анализ части коллекции булл Гебеклы-депе выявил разнообразие сюжетов. Довольно большое количество булл было оттиснуто печатями с геометрическим орнаментом, восходящим к традициям сфрагистики эпохи бронзы Мервского оазиса ${ }^{5}$. В меньшей мере, но в рамках этой традиции, фигурируют и оттиски с изображением «сцен терзания» и борьбы человека с животным, относящиеся к обширной группе антропоморфных и зооморфных сюжетов гебеклинских булл. При этом оттиски печатей с изображениями животных отличаются значительным разнообразием. Наряду с реальными (конь, олень, лев, антилопа, заяц, орел и проч.), в ней представлены и фантастические существа (Пегас, грифон, гиппокамп).

Наибольший исследовательский интерес вызывает в настоящее время довольно представительная группа булл с сюжетами «идеологической» направленности, суть которой заключается в прославлении (и обожествлении) царя и царской власти. Речь идет о буллах, которые, думается, отражают идею обожествления представителей династии Аршакидов, и, таким образом, являются важным элементом в идеологической доктрине Парфянской династии, стремившейся с определенного момента своей истории подчеркнуть, что власть царей находится под божествен ной защитой (Amm. Marcell. XXIII, 6, 4sq.). Печати этой группы, отличающиеся зачастую от остальных как качеством изображения, так и формой и размерами, принадлежали, очевидно, царским чиновникам-магистратам и несли изображения, отражающие официальную идеологию. При этом «сценография», призванная донести эту идею, была самая разнообразная. Идея обожествления царской власти находит свое выражение и в сценах увенчания царя богиней (Тюхе), и в сценах царской охоты (в присутствии богини Ники), и в сцене инаугурации царя все той же богиней Тюхе.

Наиболее ярко эта идея отражена, на наш взгляд, в булле ${ }^{6}$ (рис. 3) - оттиске большой печати, на которой изображен царь-всадник перед алтарем огня с паря-

\footnotetext{
3 Солдаты гарнизона размещались, по всей видимости, во внутристенных коридорах крепостных стен, также разделенных на определенном этапе на небольшие помещения.

4 Кошеленко, Бадер, Гаибов 1991, 5-18; Bader, Gaibov, Koshelenko 1991, 61-78; Кошеленко, Гаибов 1995, 194-203; Koshelenko 1997, 377-383; Gaibov 1997, 385-394; Bader, Gaibov, Koshelenko 1998, 24-37; Гаибов, Кошеленко 2001, 71-78; Гаибов 2004, 69-74; Кошеленко 2004, 144-146; Гаибов 2005, 37-45; Кошеленко 2005, 45-56; Gaibov 2007, 285-294; Гаибов 2008, 118-121; Gaibov, Košelenko 2008, 99-107; Gaibov 2011, 303-308.

5 Gaibov 1997, 385-394.

6 Гаибов 2004, 69-74.
} 

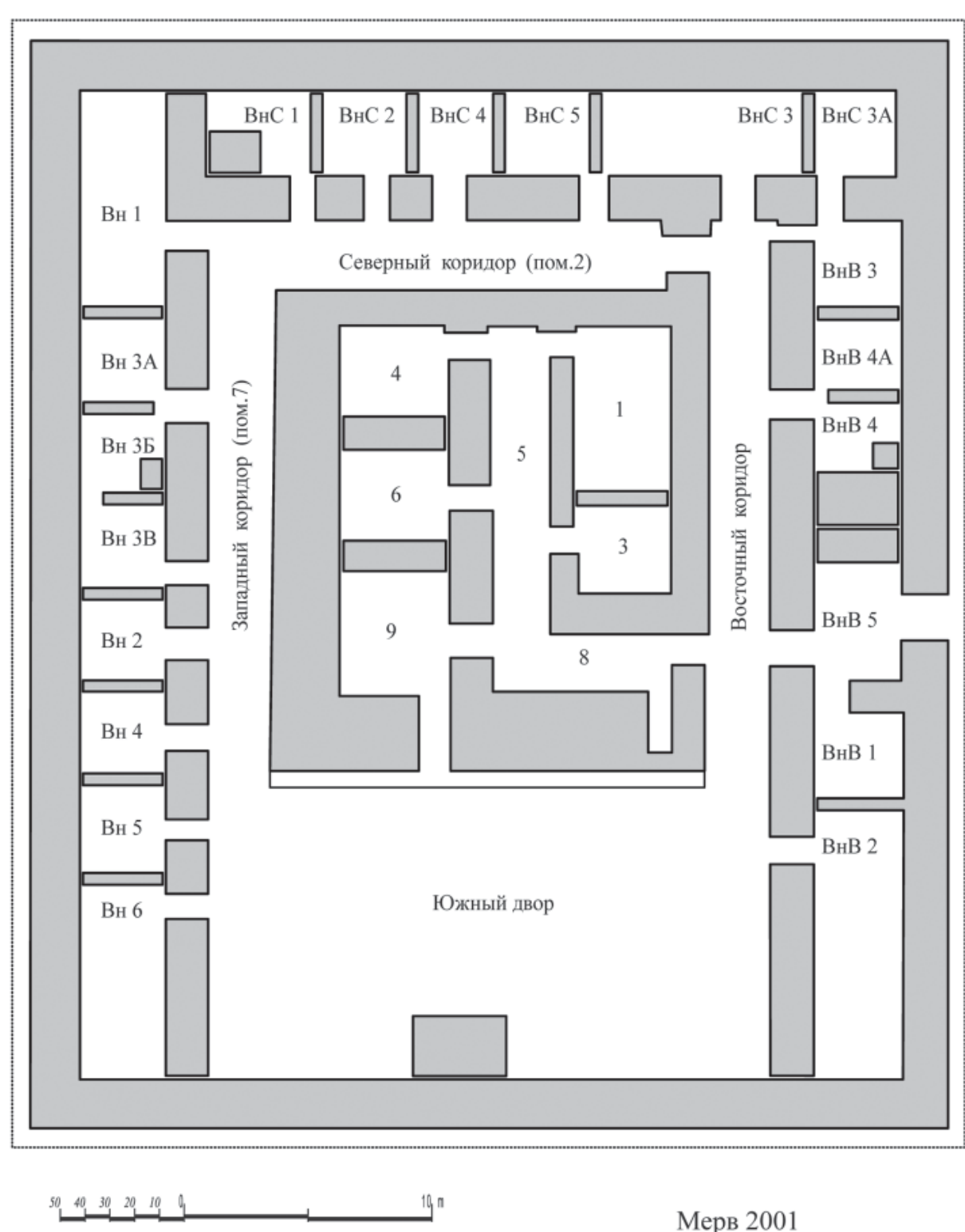

Мерв 2001

Гебеклы

Раскоп I

План центрального здания

с элементами реконструкции.

Рис. 2. Гебеклы-депе. План центрального здания (с элементами реконструкции А. Наумова) 


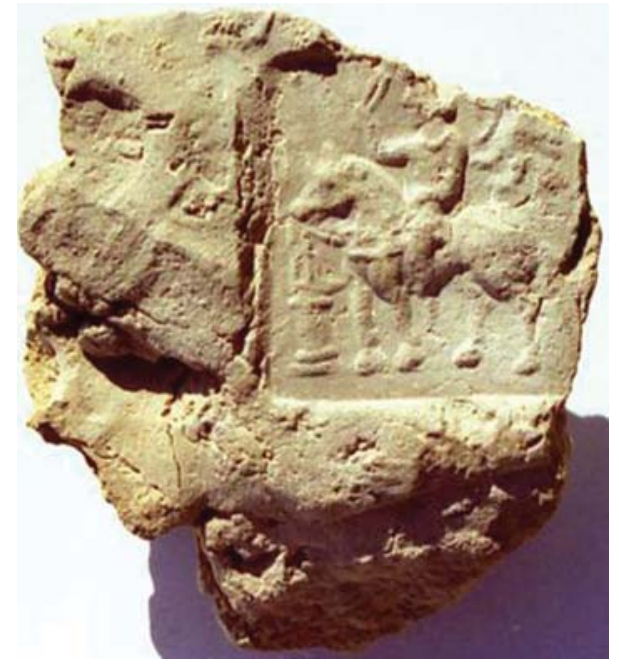

Рис. 3. Булла с изображением царявсадника перед алтарем огня щей за его спиной птицей (орел?) с развевающимися в клюве лентами. Уникальность его, помимо размеров ( $\approx 5 \times 5 \mathrm{~cm})$, заключается в том, что в данной композиции собраны, едва ли не в единственном экземпляре, три отдельных элемента: царь-всадник, птица за спиной царя, царь у алтаря. Все эти элементы в отдельности представлены в парфянском официальном искусстве, но, насколько мне известно, нет ни одного примера, когда они собраны в единой композиции. В поднятой руке всадник держит предмет, очень похожий на сложенную вдвое плеть. Все эти элементы, вкупе с хорошо заметной гривной на шее персонажа, не оставляют сомнений в царском достоинстве всадника. Вопервых, алтарь, над которым возносится пламя, вызывает прямую ассоциацию с негасимым династийным огнем Аршакидов в Асааке в Астауэне, возжженном в честь Арсака, провозглашенного здесь царем (Isid. Mans. Parth. 11). Во-вторых, «царственная птица» несет в клюве ленту-диадему - атрибут царской власти. В-третьих, плеть в руке всадника также является символом царской власти у скифских народов, наряду со скипетром либо копьем (см. Herod. IV.1.3-4). Таким образом, сюжет, представленный на оттиске, является ярким проявлением официальной идеологии прославления царской власти, в данном случае, видимо, местной династии - одной из ветвей рода Аршакидов. Наличие сразу нескольких атрибутов царского достоинства персонажа не оставляет сомнений в такой трактовке.

Несколько упрощенным вариантом изображения царя-всадника является группа булл, не столь репрезентативная, но не менее важная, где за спиной царя парит орел с развевающейся лентой. Так, на одной из них (№ 89-32) (рис. 4) мы видим всадника с парящей за его спиной птицей. Плохое качество глины, на которой оттиснута печать, не позволяет разглядеть все детали, однако наличие диадемы в клюве птицы представляется почти несомненным. Кроме того, в силу фрагментарности оттиска нет возможности говорить о завершенной композиции. В случае, если на несохранившейся части оттиска присутствовал алтарь, данная булла может быть отнесена к описанному выше оттиску печати. К этой категории можно отнести и две буллы, найденные в 1993 и 1995 гг.

С определенной степенью вероятности к рассматриваемой категории можно отнести и группу из трех булл с оттиском, сделанным, возможно, одной печатью, со сценой боя, в котором всадник стремится длинным копьем поразить противостоящего ему пехотинца, вооруженного, по всей видимости, мечом ${ }^{7}$ (рис. 5). К сожалению, очень плохое качество глины, на которой были оттиснуты изображения,

\footnotetext{
${ }^{7}$ Gaibov, Košelenko 2008, 99-107.
} 


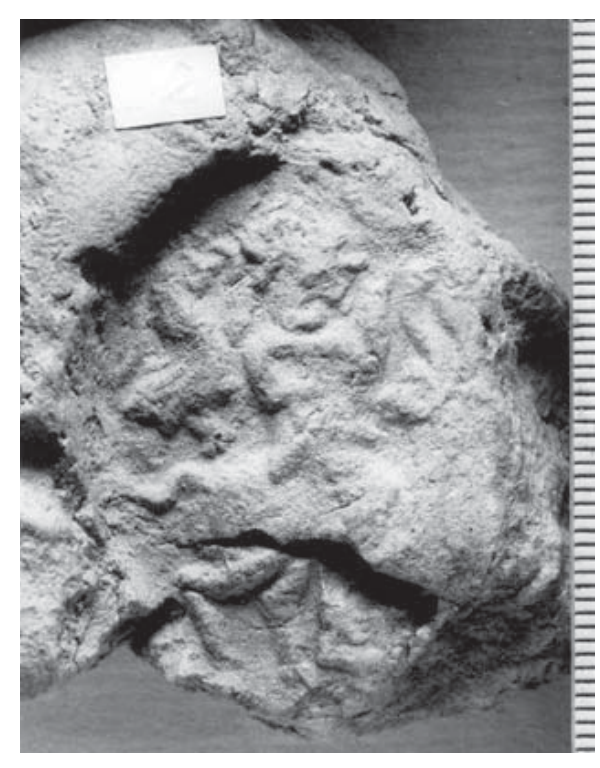

Рис. 4. Булла с изображением царявсадника с орлом за спиной

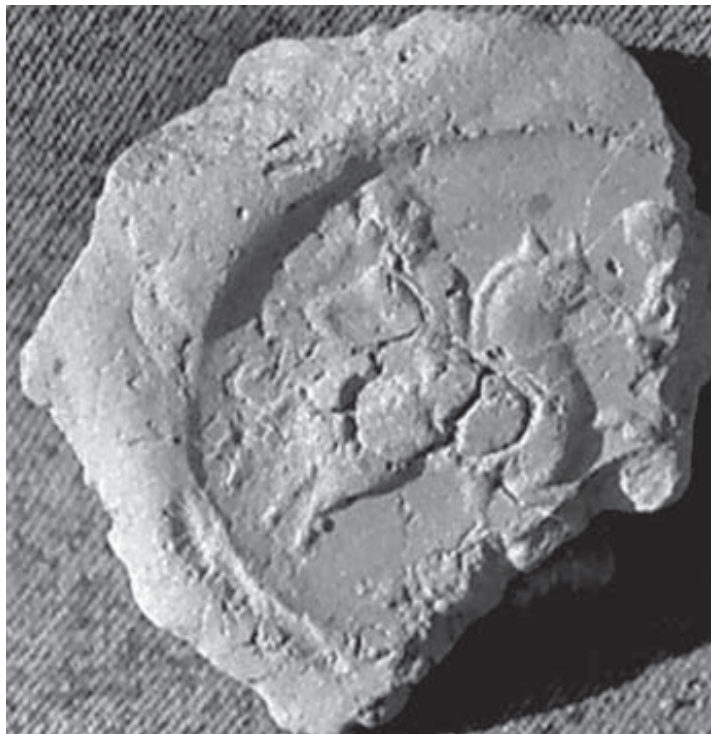

Рис. 5. Сцена с изображением битвы всадника с пехотинцем

а также фрагментарность булл затрудняют восприятие сцены, однако составленная на основе всех трех экземпляров реконструкция дает возможность восстановить всю сцену (рис. 6). В связи с интерпретацией конного персонажа именно как царя, а не абстрактного всадника, уместно вспомнить, что в Парфии, как и во всем эллинистическом и постэллинистическом мире, царь доказывал свое право на власть военными победами. Из источников нам известно, что многие парфянские цари лично возглавляли свое войско в бою, а некоторые из них (например, Фраат II и Артабан I) погибли на поле боя (Iust., 42.1.5, 42.2.2). Косвенным свидетельством такого участия в бою является наличие термина nikatōr в титулатуpe парфянских царей, представленного на многочисленных выпусках их монет ${ }^{8}$. Кроме того, интерпретация всадника как царствующей особы на изучаемом оттиске подтверждается наличием тиары с повязанной поверх нее диадемой, что являлось одним из важнейших признаков царской власти Аршакидов.

Еще один сюжет, обнаруженный на гебеклинских буллах, который следует отнести к данной категории, представлен на оттиске печати с изображением царской охоты (рис. 7). Однако первое такое изображение, абсолютно идентичное представленному на данной булле, было обнаружено на Гебеклы-депе в 1982 году, еще за несколько лет до находки первых булл (рис. 8). Это был фрагмент кувшина с нанесенным на него оттиском, на котором изображена фигура всадника с натянутым луком в руках, преследующего рогатое животное, по всей видимости, антилопу. Позади всадника парит крылатая богиня Ника с венком в руках. При этом руки богини с венком опущены вниз, к крупу коня, а не подняты над головой центрально-

\footnotetext{
8 Sellwood 1980, 87 , type 33; Vardanyan 2001,63 , no. 5.7.9.11; 69 , no. 8; 70, no. 5; 71, no. 5; 74, no. $5-7.9)$
} 


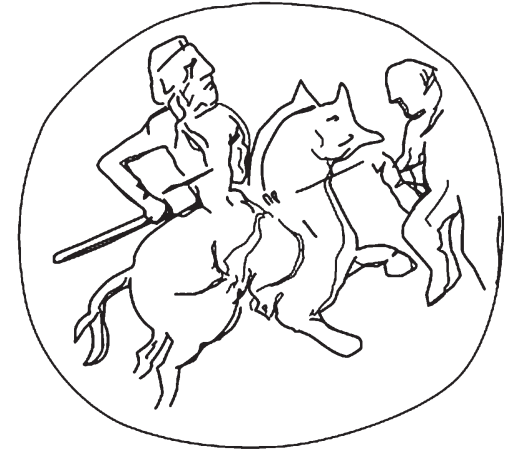

Рис. 6. Сцена с изображением битвы всадника с пехотинцем (реконструкция А. Наумова)
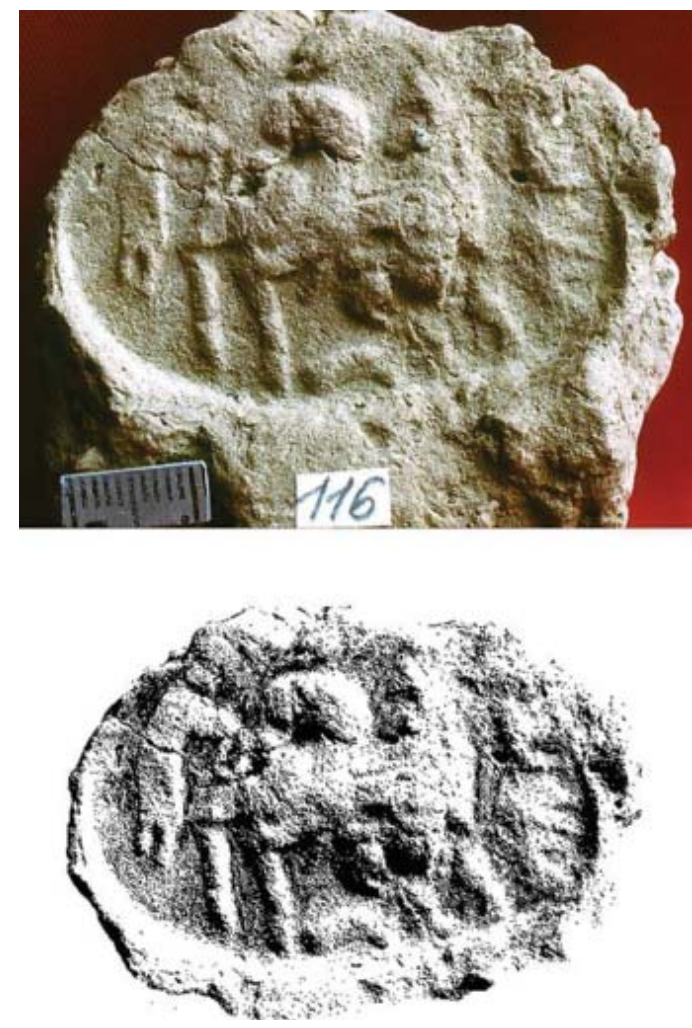

Рис. 7. Булла с изображением царской охоты (прорисовка А. Наумова) го персонажа, что, очевидно, связано с ограниченностью пространства в поле печати, не позволившем резчику правильно построить композицию. О том, что в представленном персонаже мы имеем дело именно с царем (или местным правителем) говорит целый ряд признаков. Во-первых, присутствие в сцене богини Ники. Во-вторых, о том же, очевидно, должны свидетельствовать и кисти-тассели, свисающие по бокам коня, прикрепленные к седлу или чепраку. Подобные элементы конского убора, получившие довольно широкое распространение в сасанидский период, хотя и крайне редко, но присутствуют на произведениях искусства парфянского времени. Достаточно привести в пример изображение царя-всадника на рельефе из Хунг-и Аждар (Хунг-и Наврузи) ${ }^{9}$, или рельеф в Фирузабаде с изображением сцены победы Ардашира I над последним парфянским царем Артабаном IV $(\mathrm{V})^{10}$. И хотя последний пример по формальным обстоятельствам относится к раннесасанидскому времени, указанными тасселями украшены кони не только сасанидских принцев и царя, но и конь Артабана. Наконец, общеизвестно, что охота, также, как и война, являлись одним из важнейших проявлений царственной деятельности у иранских народов с глубокой древности. Об огромной роли охоты в жизни персов свидетельствуют как нарративные источники, так и многочисленные произведения искусства, представленные в каменных рельефах, торевтике, терракоте и др.

На булле, обнаруженной на Гебеклы-депе спустя несколько лет после находки штампа на стенке сосуда, изображена аналогичная сцена, но ма-

\footnotetext{
9 Vanden Berghe 1963, 155-168 pl. 53-55; Colledge 1977, 92 pl. 17; Литвинский 2002, 197.

10 Herrmann 1969, 71 pl. I/B; Gall, von, 1990, 20-30. Abb. 3. Taf. VIII; Литвинский 2002, 197.
} 

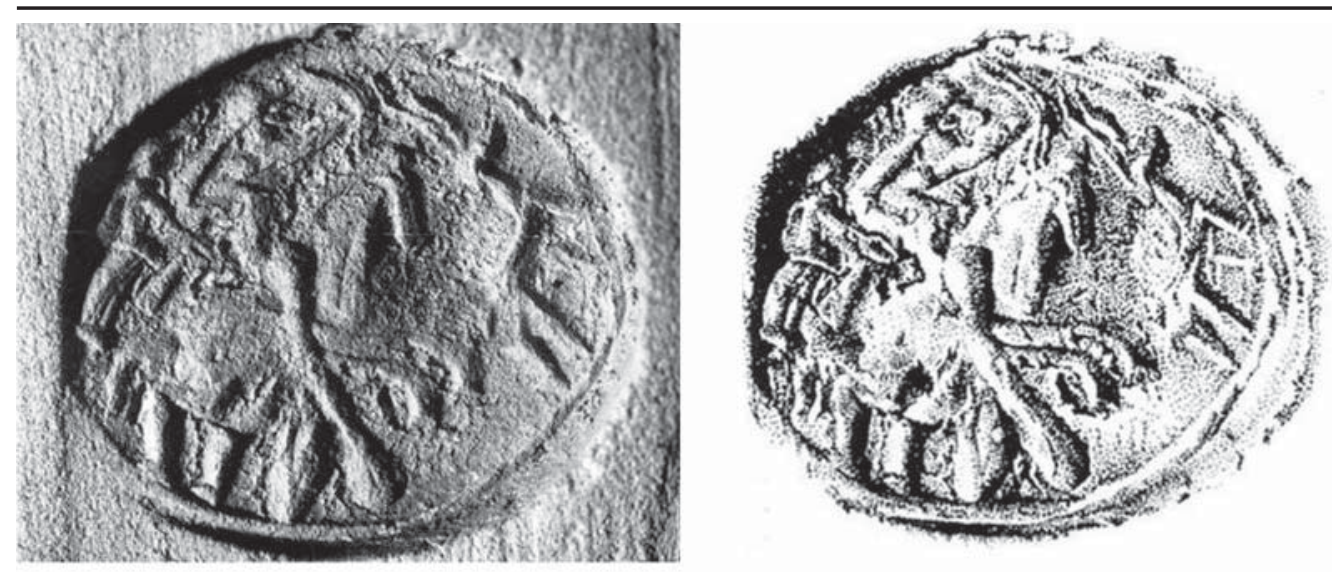

Рис. 8. Штамп на керамике с изображением царской охоты (прорисовка А. Наумова)

стерство резчика оставляет желать много и много лучшего. Попытка вписать в поле печати всех участников сцены далась мастеру труднее, чем резчику печати, оттиснутой на кувшине. Особенно заметно это проявляется в фигуре Ники, которая буквально повисла на крупе коня, а венок, который и в первом случае находился не над головой царя, а где-то в районе крупа, вообще опирается на хвост коня. Антилопа уже никуда не убегает, а просто стоит столбиком, да и конь находится далеко не в «летящем галопе». Однако все перечисленные художественные недостатки ни в коей мере не умаляют важности самого сюжета со сценой царской охоты как важного элемента в прославлении царя и царской династии.

На одной из фрагментированных булл гебеклинской коллекции (№ 89-348) представлена мужская фигура, восседающая на троне с вытянутой правой рукой, на которой стоит женская фигурка, очевидно, изображающая богиню Нику, в свою очередь, протягивающую сидящему гирлянду или кольцо (рис. 9). К сожалению,

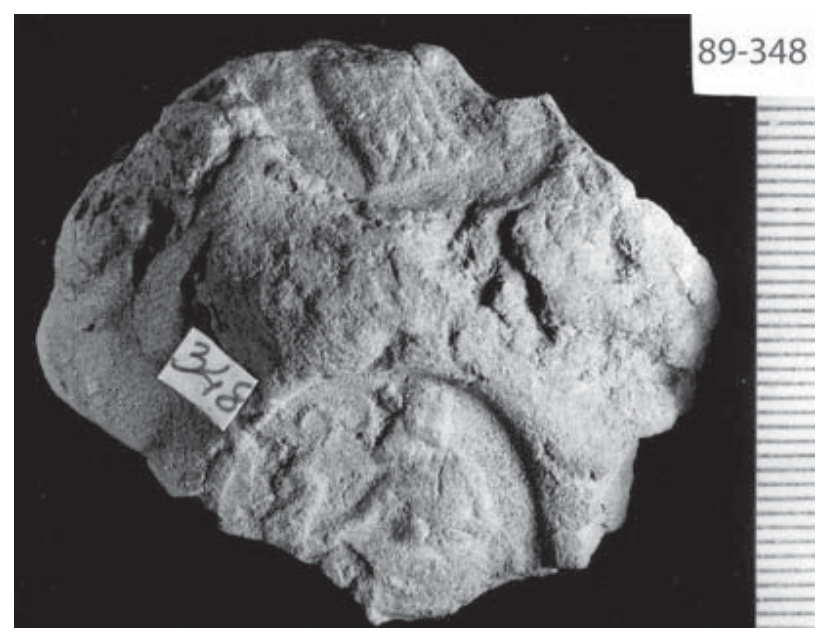

Рис. 9. Булла с изображением царя с Никой 


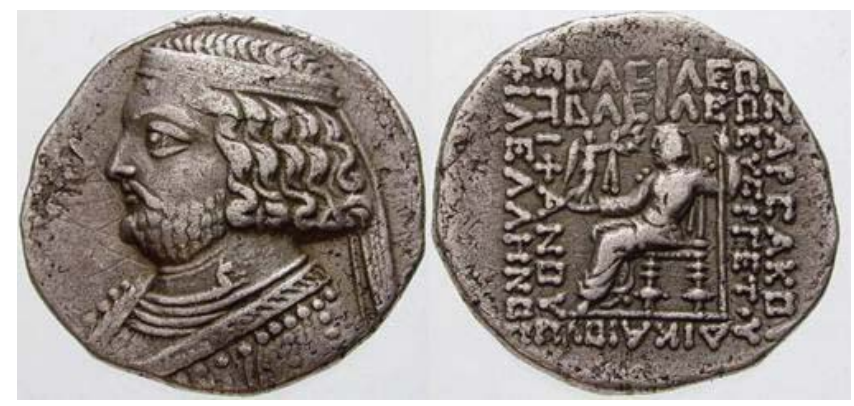

Рис. 10. Тетрадрахма Орода II

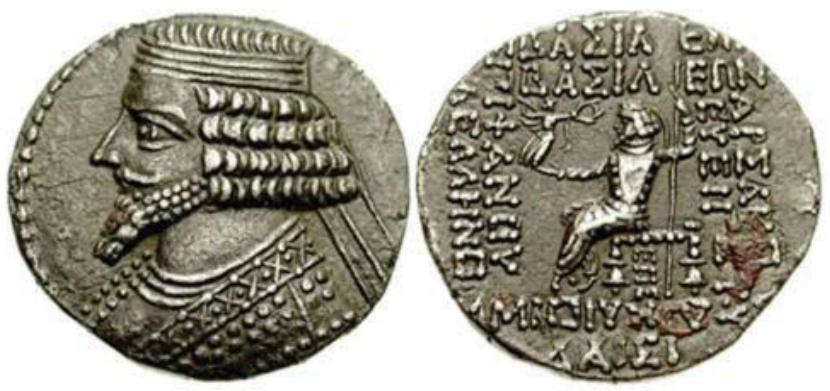

Рис. 11. Тетрадрахма Фраата IV

и в данном случае оттиск получился некачественным, однако, поскольку сходный сюжет присутствует на нескольких сериях тетрадрахм двух правивших один за другим парфянских царей - Орода II (рис. 10) и Фраата IV (рис. 11) ${ }^{11}$, можно достаточно уверенно говорить о том, что здесь мы имеем дело с изображением царя, держащего на вытянутой руке богиню Нику. Наличие в композиции гирлянды, перевитой лентами, явно ассоциируется с «кольцом власти», широко представленным на памятниках искусства позднепарфянского и раннесасанидского времени в сценах инвеституры, когда божество передает его царю или правитель вручает вассалу ${ }^{12}$. Можно предположить, что прототипом этого «кольца власти» была диадема, являвшаяся типичным символом власти в эллинистическом мире.

Особого внимания в рамках рассматриваемой категории булл заслуживает, несомненно, группа из четырех фрагментированных оттисков печатей (или, вероятно, одной печати) квадратной формы, на которых представлены мужские и женские фигуры, расположенные по обе стороны алтаря (огня?).

Данная группа булл была обнаружена на полу южного двора (или айвана), также, как и первая из рассмотренных в статье булл, вне места нахождения основной массы булл, вскрытых в промазках между полами обводных коридоров центрального комплекса (рис. 12). Мужской персонаж, расположенный справа (по

11 Sellwood 1980, 152, type 48, 1-5; 174, type 54, 1-6.

12 Kawami 1987, 45-51. 
отношению к зрителю) от алтаря, облачен в типичный парфянский костюм, состоящий из куртки и шаровар. О высоком (царском?) статусе его свидетельствует (хотя и с трудом различимая) диадема, охватывающая характерную прическу в виде буклей. В левой, согнутой в локте руке он держит некий предмет, а правая опущена к верхней площадке алтаря, в центре которого поднимается столб огня (или возвышается пальмовая ветвь?). По другую сторону от жертвенника расположена женская фигура в длинном облегающем фигуру платье. Правая рука ее также согнута в локте, левая рука, ввиду плохой сохранности всех четырех оттисков, не прослеживается.

Особое значение данной группе булл придает, помимо неординарного и весьма красноречивого сюжета, наличие надписей, расположенных вертикально за спинами персонажей. Учитывая то обстоятельство, что даже среди частично изученной коллекции, буллы с надписями исчисляются единицами, наличие экземпляров, содержащих текст, привлекает особое внимание. Долгое время эти надписи оставались непрочитанными, и лишь буквально недавно А.Б. Никитин предложил свое прочтение ${ }^{13}$, поэтому здесь можно ограничиться кратким описанием их содержания. При этом следует сразу оговориться, что, как и большинство гебеклинских булл, данная группа с надписями также в той или иной степени повреждена при вскрытии контейнеров, которые они опечатывали. Поэтому прочтение надписей, сделанных парфянским письмом, носит предположительный характер и восстанавливается путем сопоставления и сравнения отдельных элементов на всех четырех буллах ${ }^{14}$.

Надпись за спиной мужского персонажа читается как hw[twy $]^{15}$ - xwadaw «господин», «владетель», а надпись слева, за спиной женского персонажа, - как имя собственное: 'trwn - Ādurān, Адуран, образованного от слова adur - «огонь» ${ }^{16}$. Как известно, на иранских печатях, парфянских и сасанидских, обычно содержится имя или имя и титул. Реже приводится только титул, но с указанием места (к примеру, «марзбан Мерва»). В нашем случае имеются две строчки, что может трактоваться, как имя и титул. Таким образом, можно предположить, что надпись не связана со сценой, представленной на оттиске. Она представляет собой имя и титул владельца печати, очевидно, чиновника весьма высокого ранга. Сам же сюжет может быть интерпретирован как сцена инвеституры богиней Тюхе (?) правителя, вероятно, представителя местной ветви династии Аршакидов (или сатрапа?). В этой сцене наиболее ярко и недвусмысленно отражена идея прославления царя и царской власти.

Анализ этой группы булл и имеющихся аналогий, представленных на печатях, в каменных рельефах, в глиптике и в живописи из различных частей иранского мира, начиная с ахеменидского и вплоть до сасанидского времени, позволяет с большой долей уверенности говорить о том, что данная иконографическая схема,

\footnotetext{
13 Автором совместно с А.Б. Никитиным подготовлена к публикации статья, посвященная нескольким оттискам печатей, содержащих надписи.

14 Как уже отмечалось выше, оттиск на всех четырех экземплярах был сделан, очевидно, одной печатью.

15 См., например, Gignoux 1972, 24. Не исключено и прочтение этого слова как патронима hw[slwy] - Хусрав.

16 Gignoux 1972, 17.
} 

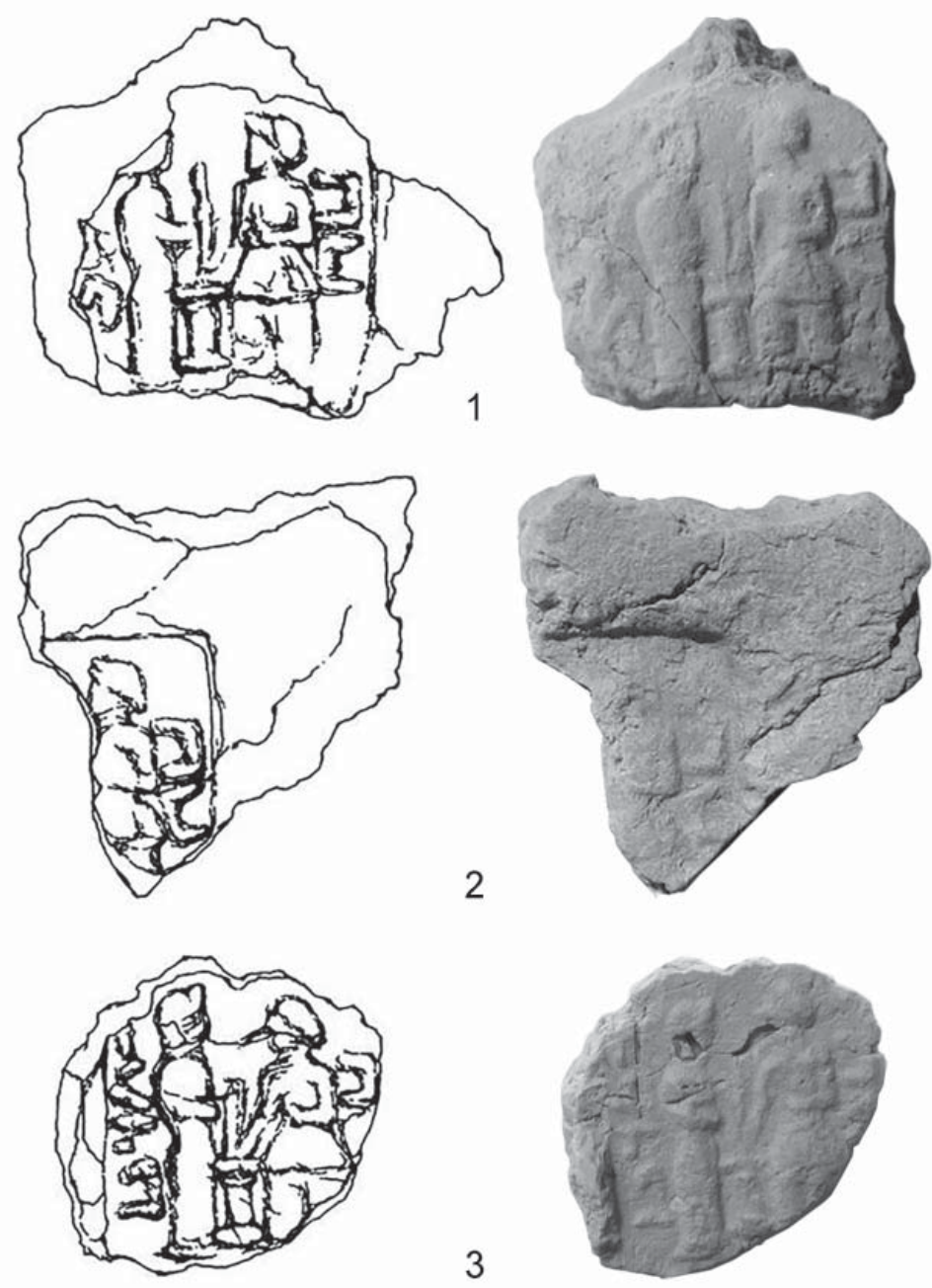

3
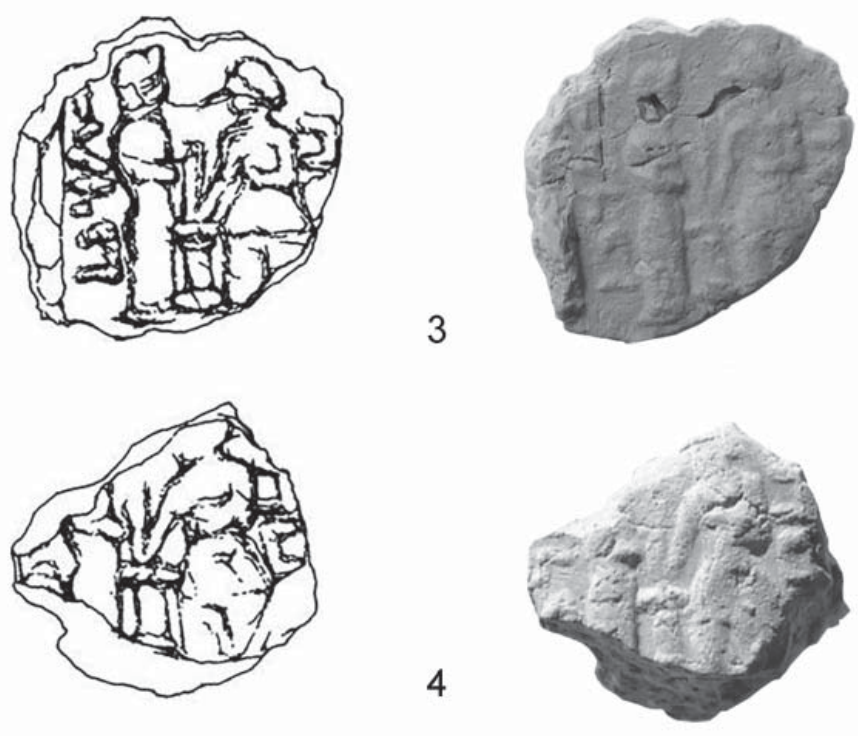

$5 \mathrm{~cm}$

Рис. 12. Группа булл со сценой инвеституры (прорисовки А. Наумова) 
отражающая идею получения инсигний власти правителем непосредственно от божества, сложилась в мире ираноязычных народов с самого начала самостоятельного существования иранского искусства и прошла большой путь развития и трансформации. Понятно, что в различные периоды и в различных художественных школах в нее вкладывалось не всегда одинаковое содержание и методы передачи ее могли различаться, но сама схема продолжала жить.

В ахеменидский период данная иконографическая схема была распространена как в монументальном искусстве, так и особенно широко в глиптике ${ }^{17}$. Она использовалась в течение всего ахеменидского периода, при этом печати производились как в «столичных» мастерских, так и в местных. В последнем случае они были невысокого художественного уровня.

Использование этой иконографической схемы в парфянское время стало еще более широким. В монументальном искусстве она зафиксирована в настенной живописи и в рельефах.

Примеры использования данного сюжета в живописи дают нам Дура-Европос $^{18}$ и Пальмира ${ }^{19}$. В условиях полисной среды сюжет приобретает более демократический характер, что выражается в замене прежней пары персонажей (божество - царь) на новых, как правило, более многочисленных (жрецы, военачальники, знатные граждане города).

Сцена жертвоприношения перед алтарем огня была чрезвычайно популярна в Иране парфянского времени (Элимаида, иранский Курдистан, Персида и др.) ${ }^{20}$.

Видимо, влиянием парфянского наследия объясняется и характер изображения сцены инвеституры Ардашира I, основателя Сасанидского государства, представленного на огромном скальном рельефе близ Фирузабада. Здесь по обе стороны от алтаря огня изображены Ахура-Мазда и царь, которому верховный бог вручает символ власти - диадему. Позади Ардашира стоят четыре персонажа, изображенные в меньшем масштабе, чем божество и царь (очевидно, это свита и сыновья царя) ${ }^{21}$.

Рельеф в Фирузабаде - практический единственный известный образец этого вида искусства сасанидского времени, на котором изображен алтарь огня. Постепенно в сасанидском официальном искусстве эта схема если не исчезает окончательно, то подвергается весьма сильной трансформации: наряду с исчезновением алтаря меняется и облик основных персонажей - теперь и божество, и царь изображены в виде всадников. На одном из рельефов в Накш-и Рустаме тот же Ардашир I в той же сцене инвеституры изображен уже конным ${ }^{22}$. Однако и эта «модернизированная» иконографическая схема остается недолговечной. По наблюдению Р. Гиршмана, начиная с конца III в. н.э. «сцена конной инвеституры уже покинута в рельефных изображениях» ${ }^{23}$. Сцена инвеституры царя Нарсе в Накш-и Рустаме

\footnotetext{
17 См. Moorey 1979, 218-226 figs. 2 b-d; 3 a,c,d. Автор считает этот сюжет типично иранским, не имеющим прототипов в искусстве Переднего Востока предшествующего периода.

18 См. Cumont 1926, 58-64. Tabs. XXXI-XLI; Кошеленко 1966, 184-186 рис. на с. 185; Colledge 1977,119 pl. 48 sq.

19 См., например, Colledge 1976, 51 pl. 41.

20 См. Colledge 1976, 92 pl. 18; Ghirshman 1976, 21-23, 26, 271. Colledge 1976, 99 pl. 31 b.

21 Ghirshman 1962, 131 fig. 167.

22 Ghirshman 1962, 133, fig. 168.

23 Ghirshman 1962, 176 fig. 218.
} 
уже соответствует новой формуле: Нарсе получает инсигнии власти из рук Анахиты пешим и в отсутствии алтаря огня.

В то же время сцена со стоящим перед алтарем огня царем является самой распространенной на монетах Персиды селевкидского, парфянского и сасанидского времени ${ }^{24}$, имеющих при этом поразительное сходство с упоминавшимися уже изображениями на печатях ахеменидского периода.

Возможно, последним «отблеском» этой иконографической схемы является присутствие на оборотной стороне сасанидских монет (самые основные типы) двух фигур по обе стороны от алтаря. Р. Гебль, первоначально с большой осторожностью определявший их как «attendants» ${ }^{25}$, затем уточнял, что это могли быть жрецы $^{26}$, а далее указывал, что, начиная с монет Варахрана I, левая фигура является изображением царя, не исключая при этом, что обе фигуры иногда могут быть «удвоенным» изображением царя.

Подводя итоги проведенному анализу данной иконографической схемы, можно отметить несколько моментов.

Во-первых, следует признать очевидным, что сюжет: царь получает инсигнии власти от божества, находясь перед алтарем огня, - сформировался в иранском мире.

Во-вторых, в Маргиане эта идея еще в парфянское время продолжала существовать, так сказать, «в чистом виде», не претерпев особых иконографических и идеологических изменений по сравнению с ранними этапами ее существования. В этом можно видеть отличие от более западных регионов государства (Дура-Европос, Пальмира и др.), где (в условиях города) происходит некоторая «демократизация» сюжета, когда сцена трансформируется в обыкновенное жертвоприношение.

Данный сюжет вполне может быть отнесен к уже отмечавшейся нами ранее группе булл, отражающих официальную идеологию Аршакидской династии. Сама же печать с таким изображением принадлежала, как уже было сказано, кому-то из царских чиновников.

\section{ЛИТЕРАТУРА}

Гаибов, В.А. 2004: Маргианская булла с изображением царя-всадника. ВДИ 2, 69-74.

Гаибов, В.А. 2005: Буллы сасанидского и парфянского времени на востоке Ирана: Ак-депе и Гебеклы-депе (попытка сравнения). ПИФК XV, 37-45.

Гаибов, В.А. 2008: Образ царя в искусстве Маргианы парфянского времени. В сб.: Труды II (ХVIII) Всероссийского археологического съезда в Суздале. II. М., 118-121.

Гаибов, В.А., Кошеленко, Г.А. 2001: Буллы из раскопок Гебеклы-депе (Туркменистан). ВДИ 2, 71-78.

Гаибов, В.А., Кошеленко, Г.А. 2007: Крепость на границе Мервского оазиса: Гебеклы-депе. Antiquitas aeterna. Поволжский антиковедческий журнал 2, 360-374.

Кошеленко, Г., Бадер, А., Гаибов, В. 1991: Парфянские буллы из раскопок Гебеклы-депе (Маргиана). Информачионный бюллетень МАИКЦА 18, 5-18.

Кошеленко, Г.А. 1966: Культура Парфии. М.

\footnotetext{
24 Ghirshman 1962, 131; Naster 1970, 125-129 pl. V, 1-14.

25 Göbl 1971, 5.

26 Göbl 1971, 18.
} 
Кошеленко, Г.А. 2004: Булла с изображением двугорбого верблюда с городища Гебеклы. PA 3, 144-146.

Кошеленко, Г.А. 2005: Буллы Старой Нисы и Гебеклы-депе: сопоставление. ПИФК XV, $45-56$.

Кошеленко, Г.А., Гаибов, В.А., Бадер, А.Н. 1995: Две богини? ВДИ 2, 194-203.

Кошеленко, Г.А., Никитин, А.Б 1991: Монетные находки и проблемы стратиграфии Гебеклы-депе. Информационный бюллетень МАИКЦА 18, 108-121.

Литвинский, Б.А. 2002: Бактрийцы на охоте. Записки Восточного отделения Российского археологического общества. Новая серия. Т. I (XXVI), 181-213.

Новиков, С.В., Новикова, О.Г., Кошеленко, Г.А. 1994: Слои эпохи Яз-ІІІ на Гебеклы-депе. Вестник Московского университета 8, 6, 69-76.

Пугаченкова, Г.А. 1958: Пути развития архитектуры Южного Туркменистана поры рабовладения и феодализма. (Труды ЮТАКЭ. Т. VI). М.

Bader, A., Gaibov, V., Koshelenko, G. 1991: New Evidence on Parthian Sphragistcs. Bullae from the Excavations of Göbekly-depe in Margiana. Mesopotamia XXV, 61-78.

Bader, A., Gaibov, V., Koshelenko, G. 1998: Monarchic Ideas in Parthian Margiana as shown on Seals. In: V.S. Curtis, R. Hillenbrand, J.M. Rogers (eds.), The Art and Archaeology of Ancient Persia. New Light on the Parthian and Sasanian Empires. London-New-York, 24-37.

Colledge, M.A.R. 1977: Parthian Art. London.

Cumont, F. 1926: Fouilles de Doura-Europos. Paris.

Gaibov, V. 1997: Bullae from Gebekly-depe (Margiana). Bronze Age Traditions in Parthian Sphragistics. In: M.-F. Boussac, A. Invernizzi (ed.), Archives et sceaux du monde hellénistique (BCH Supplement 29), 385-394.

Gaibov, V. 2007: The Bullae of Gobekly-depe. In: After Alexander. Central Asia before Islam. Proceedings of the British Academy 133, 285-294.

Gaibov, V. 2011: Tsarskaya okhota - novyy syuzhet v parfyanskoy sfragistike Margiany. In: A. Invernizzi (ed.), Un impaziente desiderio di scorrere il mondo. Firenze, 303-308.

Gaibov, V.A., Košelenko, G.A. 2008: A horseman chairing a foot-soldier: a new subject in Parthian glyptic art. PARTHICA. Incontri di Culture nel Mondo Antico 10, 99-107.

Gall, H., von. 1990: Das Reiterkampfbild in der iranischen und iranisch beeinflußten Kunst parthischer und sasanidischer Zeit. Berlin.

Ghirshman, R. 1962: Iran. Parthes et Sassanides. Paris.

Ghirshman, R. 1976: Terrasses sacrées de Bard-è Néchandeh et Masjid-i Solaiman. I. Paris.

Gignoux, Ph. 1972: Glossaire des Inscriptiones Pehlevies et Parthes (Corpus Inscriptionum Iranicarum. Supplementary Series. Vol. I). London.

Göbl, R. 1971: Sasanian Numismatics. Braunschweig.

Herrmann, G. 1969: The Dārābgird Relief - Ardashīr or Shāhpūr? A Discussion in the Context of Early Sasanian Sculpture. Iran VII, 71, 63-88.

Kawami, T. 1987: Monumental Art of the Parthian Period in Iran. Acta Iranica 26, 45-51.

Koshelenko, G. 1997: Bullae from Göbekly-depe. General Problems and Main Subjects. In: Archives et sceaux du monde hellénistique (BCH Supplement 29), 377-383.

Moorey, P.R.S. 1979: Aspects of Worship and Ritual on Achaemenid Seals. In: Akten des VII. Internationalen Kongresses für iranische Kunst und Archäologie. München, 7-10 September 1976. Berlin, 218-226.

Naster, P. 1970: Fire-altar or fire-tower on the coins of Persis? Orientalia Lovaniensia periodica I, 125-129.

Sellwood, D. 1980: An Introduction to the Coinage of Parthia. London.

Vanden Berghe, L. 1963: Le relief parthe de Hung-i Naurūzī. Iranica Antiqua III/2, 155-168.

Vardanyan, R. 2001: Tendenze culturali e ideologiche nell'impero partico riflesse dalla monetazione. PARTHICA. Incontri di Culture nel Mondo Antico 3, 25-132. 


\section{REFERENCES}

Bader, A., Gaibov, V., Koshelenko, G. 1991: New Evidence on Parthian Sphragistcs. Bullae from the Excavations of Göbekly-depe in Margiana. Mesopotamia XXV, 61-78.

Bader, A., Gaibov, V., Koshelenko, G. 1998: Monarchic Ideas in Parthian Margiana as shown on Seals. In: V.S. Curtis, R. Hillenbrand, J.M. Rogers (eds.), The Art and Archaeology of Ancient Persia. New Light on the Parthian and Sasanian Empires. London-New-York, 24-37.

Colledge, M.A.R. 1977: Parthian Art. London.

Cumont, F. 1926: Fouilles de Doura-Europos. Paris.

Gaibov, V. 1997: Bullae from Gebekly-depe (Margiana). Bronze Age Traditions in Parthian Sphragistics. In: M.-F. Boussac, A. Invernizzi (ed.), Archives et sceaux du monde hellénistique (BCH Supplement 29), 385-394.

Gaibov, V.A. 2004: Margianskaya bulla s izobrazheniem tsarya-vsadnika [Bulla from Margiana with the portrait of a mounted King]. Vestnik drevney istorii [Journal of Ancient History] $2,69-74$.

Gaibov, V.A. 2005: Bully sasanidskogo i parfyanskogo vremeni na vostoke Irana: Ak-depe i Gebekly-depe (popytka sravneniya) [Bullae of Sasanian and Parthian time in the East of Iran: Ak-depe and Göbekly-depe (attempted comparison)]. Problemy istorii, filologii, kul'tury [Journal of Historical, Philological and Cultural Studies] XV, 37-45.

Gaibov, V. 2007: The Bullae of Gobekly-depe. In: After Alexander. Central Asia before Islam. Proceedings of the British Academy 133, 285-294.

Gaibov, V.A. 2008: Obraz tsarya v iskusstve Margiany parfyanskogo vremeni [The image of King in the art of Margiana of Parthian time]. In: Trudy II (XVIII) Vserossiyskogo arkheologicheskogo s'ezda v Suzdale [Proceedings of the II (XVIII) All-Russian Archaeological Congress in Suzdal]. II. Moscow, 118-121.

Gaibov, V. 2011: Tsarskaya okhota - novyy syuzhet v parfyanskoy sfragistike Margiany [King's hunt - a new plot in the Parthian sphragistics of Margiana]. In: A. Invernizzi (ed.), Un impaziente desiderio di scorrere il mondo. Firenze, 303-308.

Gaibov, V.A., Koshelenko, G.A. 2001: Bully iz raskopok Gebekly-depe (Turkmenistan) [Bullae from the excavations at Göbekly-depe (Turkmenistan)]. Vestnik drevney istorii [Journal of Ancient History] 2, 71-78.

Gaibov, V.A., Koshelenko, G.A. 2007: Krepost' na granitse Mervskogo oazisa: Gebekly-Depe [The fortress on the border of the Merv Oasis: Göbekly-depe]. Antiquitas aeterna. Povolzhskiy antikovedcheskiy zhurnal [Antiquitas aeterna. Povolzhsky journal of classical studies] 2, 360-374.

Gaibov, V.A., Košelenko, G.A. 2008: A horseman chairing a foot-soldier: a new subject in Parthian glyptic art. PARTHICA. Incontri di Culture nel Mondo Antico 10, 99-107.

Gall, H., von. 1990: Das Reiterkampfbild in der iranischen und iranisch beeinflußten Kunst parthischer und sasanidischer Zeit. Berlin.

Ghirshman, R. 1962: Iran. Parthes et Sassanides. Paris.

Ghirshman, R. 1976: Terrasses sacrées de Bard-è Néchandeh et Masjid-i Solaiman. I. Paris.

Gignoux, Ph. 1972: Glossaire des Inscriptiones Pehlevies et Parthes. (Corpus Inscriptionum Iranicarum. Supplementary Series. Vol. I). London.

Göbl, R. 1971: Sasanian Numismatics. Braunschweig.

Herrmann, G. 1969: The Dārābgird Relief - Ardashīr or Shāhpūr? A Discussion in the Context of Early Sasanian Sculpture. Iran VII, 71, 63-88.

Kawami, T. 1987: Monumental Art of the Parthian Period in Iran. Acta Iranica 26, 45-51.

Koshelenko, G. 1997: Bullae from Göbekly-depe. General Problems and Main Subjects. In: Archives et sceaux du monde hellénistique (BCH Supplement 29), 377-383. 
Koshelenko, G., Bader, A., Gaibov, V. 1991: Parfyanskie bully iz raskopok Gebekly-depe (Margiana) [Parthian bullae from the excavations of Göbekly-depe (Margiana)]. Informatsionnyy byulleten' MAIKTSA [Information Bulletin of the International Association for the Study of Cultures of Central Asia $]$ 18, 5-18.

Koshelenko, G.A. 1966: Kul'tura Parfii [Culture of Parthia]. Moscow.

Koshelenko, G.A. 2004: Bulla s izobrazheniem dvugorbogo verblyuda s gorodishcha Gebekly [Bulla with the image of a two-humped camel from the ancient settlement of Göbekly]. Rossiyskay arkheologiya [Russian archaeology] 3, 144-146.

Koshelenko, G.A. 2005: Bully Staroy Nisy i Gebekly-depe: sopostavlenie [Bullae from Old Nisa and Göbekly-depe: a comparison]. Problemy istorii, filologii, kul'tury [Journal of Historical, Philological and Cultural Studies] XV, 45-56.

Koshelenko, G.A., Gaibov, V.A., Bader, A.N. 1995: Dve bogini? [Two goddesses?]. Vestnik drevney istorii [Journal of Ancient History] 2, 194-203.

Koshelenko, G.A., Nikitin, A.B 1991: Monetnye nakhodki i problemy stratigrafii Gebekly-depe [Coin finds and the problems of stratigraphy of Göbekly-depe]. Informatsionnyy byulleten' MAIKTSA [Information Bulletin of the International Association for the Study of Cultures of Central Asia] 18, 108-121.

Litvinskiy, B.A. 2002: Baktriytsy na okhote [The Bactrians on the hunt]. Zapiski Vostochnogo otdeleniya Rossiyskogo arkheologicheskogo obshchestva. Novaya seriya [Notes of the Eastern Branch of the Russian Archaeological Society. New series] T. I (XXVI), 181-213.

Moorey, P.R.S. 1979: Aspects of Worship and Ritual on Achaemenid Seals. In: Akten des VII. Internationalen Kongresses für iranische Kunst und Archäologie. München 7.-10. September 1976. Berlin, 218-226.

Naster, P. 1970: Fire-altar or fire-tower on the coins of Persis? Orientalia Lovaniensia periodica I, 125-129.

Novikov, S.V., Novikova, O.G., Koshelenko, G.A. 1994: Sloi epokhi YAz- III na Gebekly-depe [Layers of the Yaz-III epoch on Göbekly-depe]. Vestnik Moskovskogo universiteta [Bulletin of the Moscow University] 8, 6, 69-76.

Pugachenkova, G.A. 1958: Puti razvitiya arkhitektury Yuzhnogo Turkmenistana pory rabovladeniya i feodalizma [Ways of development of architecture of the Southern Turkmenistan during slaveholding and feudalism]. In: Trudy YUTAKE [Works of the South Turkmenistan Archaeological Complex Mission] T. VI. Moscow.

Sellwood, D. 1980: An Introduction to the Coinage of Parthia. London.

Vanden Berghe, L. 1963: Le relief parthe de Hung-i Naurūzī. Iranica Antiqua III/2, 155-168.

Vardanyan, R. 2001: Tendenze culturali e ideologiche nell'impero partico riflesse dalla monetazione. PARTHICA. Incontri di Culture nel Mondo Antico 3, 25-132.

\title{
KING'S CULT IN PARTHIA (BULLAE FROM EXCAVATIONS AT GÖBEKLY-DEPE)
}

\author{
Vasif A. Gaibov
}

Institute of Archaeology of the Russian Academy of Sciences, Moscow, Russia gaibov@mail.ru

Abstract. The article deals with a group of impressions from seals (bullae) found during the excavation of the central building in the border fortress of the Parthian epoch, Gebeklydepe, located on the northwestern outskirts of the Merv oasis (the ancient Margiana). Bullae were found between pro-dabs of floors of the bypass corridors serving as warehouses where the 
goods and freights were opened, arriving to fortress from the capital of the satrapy, Alexandria/ Antiochia of Margiana. The special attention is drawn by a representative group of bullae with subjects of "ideological" orientation which essence consisted in glorification (and deification) of the king and the royal power. The most indicative artifacts are the bullae with the image of the king-rider in front of the fire altar with the eagle behind the back holding a belt/diadem in his beak; the king sitting on a throne with Nike entrusting him with a diadem; the battle of the king-rider with an infantryman. However the most indicative example of glorification (and deification) of the king power is a small group (of four specimens) of bullae depicting the scene of investiture of the king in front of the (fire?) altar by the goddess Tyhe. The inscriptions behind the backs of characters confirm the high status of an official who was the owner of this seal.

Keywords: Parthia, Margiana, Göbekly-depe, bullae, king’s cult 